\title{
Mycotoxin Strategies: Impact on Global Health and Wealth
}

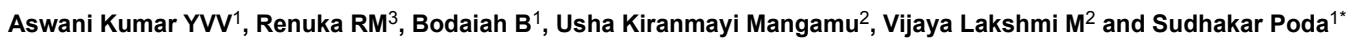

${ }^{1}$ Department of Biotechnology, Acharya Nagarjuna University, Nagarjuna Nagar, Guntur-522510, Andhra Pradesh, India

${ }^{2}$ Department of Botany and Microbiology, Acharya Nagarjuna University, Nagarjuna Nagar, Guntur-522510, Andhra Pradesh, India

${ }^{3}$ Department of Biotechnology, DRDO-BU-center for Life Sciences, Bharathiar University Campus, Coimbatore-641 046, Tamil Nadu, India

*Corresponding author: Sudhakar Poda, Department of Biotechnology, Acharya Nagarjuna University, Nagarjuna Nagar, Guntur-522510, Andhra Pradesh, India, Tel: +91-9000122929; E-mail: sudhakarpodha@gmail.com

Received date: June 28, 2016; Accepted date: Jul 27, 2016; Published date: Jul 30, 2016

Copyright: $\odot 2016$ Sudhakar $P$, et al. This is an open-access article distributed under the terms of the Creative Commons Attribution License, which permits unrestricted use, distribution, and reproduction in any medium, provided the original author and source are credited.

\begin{abstract}
Mycotoxins are toxic secondary metabolites of molds show antagonistic possessions on human beings, wildlife, and agro sector that result in mystery disorders and economic disturbances. The mycotoxins contaminated foods and fodder are omnipresent and become a global concern. Due to the consumption of contaminated food and fodder, epidemic out breaks are a frequent and a common phenomenon. The most important agriculture oriented mycotoxins are aflatoxins, possible for hepatic cancer, childhood impairment and also causes acute toxicosis; fumonisins, are linked with esophageal cancer and neural tube defects (NTDs); while immunotoxic deoxynivalenol (DON) and other trichothecenes, cause gastroenteritis; and ochratoxin A (OTA), has been connected with kidney diseases. This review primarily describes each group of mycotoxins in detail, and their adverse effects on global population health and wealth.
\end{abstract}

Keywords: Mycotoxins; Economic losses; Immuno toxic; Worldwide at risk

\section{Introduction}

Mycotoxin is a combination of the 'mykes'fungus and the Latin word 'toxicum' poison. The mycotoxin' is usually chemical products formed as secondary metabolites by a few fungi that readily colonize crops in the field or after harvest found at trace levels reserved for the relatively small (MW700), toxic, which hardly identifiable. As per the opinion of Food and Agriculture Organization (FAO) it is assessed that nearly $25 \%$ of the global fodder crops are adulterated with mycotoxins [1]. It is predicted that 200,000 people are added to the global food demand daily and by the year 2050, the world population will surpass 9 billion [2].

\section{Mycotoxin Diversity}

Mycotoxins are made of vastly diverse organic structures categorized by a range of heteroatom-containing organic chemicals found in mold-polluted food sources and may be harmful if ingested in high enough quantities or over a long enough period of time. While plentiful reviews have extensively enclosed mycotoxins biological nature, production and sound effects in human and animal health [3-5]. Fruits are highly susceptible to fungal invasion during the stage of ripening because, the $\mathrm{pH}$ of the tissue rises, softening of skin layers, accumulation of soluble carbohydrates, and deterioration of defense system happens [6]. A small number of dried fruits contamination by mycotoxins has been regulated in laws are in great demand in the food markets [7]. The Commission of the European Communities (2006, 2010) has executed strong regulations to minimize the contamination of ochratoxin $10 \mu \mathrm{g} \mathrm{kg}^{-1}$ (OTA), aflatoxin $2 \mu \mathrm{g} \mathrm{kg}^{-1}$ (AFB1), and over- all aflatoxins ( $4 \mu \mathrm{g} \mathrm{kg}^{-1}$ for the total of AFB1+AFB2+AFG1+AFG2) in dried vine fruit (currants, raisins, and sultanas).

\section{Major Mycotoxins}

The majority clusters of mycotoxins occur quite often in food commodities are released by the following five fungal origin: aflatoxins, aflatoxin-producing Aspergillus spp.; ochratoxin A produced by significant members of Aspergillus and Penicillium; trichothecenes (T-2 and HT-2 toxins are type-A trichothecene mycotoxins, and type B: deoxynivalenol (DON) zearalenone (ZON)), fumonisin $\mathrm{B} 1$ and $\mathrm{B} 2$ produced by Fusarium proliferatum, $F$. moniliforme, fusaproliferin, beauvericin, enniatins and moniliformin are included as emerging Fusarium mycotoxins,; ergot alkaloids produced by ergot fungi Claviceps purpurea; and toxins produced by Alternaria sp. are alternariol monomethyl ether (AME), alternariol $(\mathrm{AOH})$, altenuene, altertoxin, and tenuazonic acid (TA), a tetramic acid derivative.

\section{Classification of Mycotoxins}

There are more than 400 known mycotoxins out of which are six major classes of mycotoxins are frequently occurring: aflatoxins, trichothecenes, fumonisins, zearalenone, ochratoxin ergot alkaloids and Patulin (CAST Report (2003)(Table:1).

Though less stated, there are some fungal toxins, such as enniatins (ENs), alternaria toxins, moniliformin (MON), citrinin (CTN), beauvericin (BEA), cyclopiazonic acid, roquefortin $\mathrm{C}$, mycophenolic acid, penitrems, verruculogen, griseofulvin, citreoviridin, produces acute and chronic toxicity. 


\begin{tabular}{|c|c|c|c|}
\hline S.No & Mycotoxin & Organism & Remarks \\
\hline 1 & Aflatoxins & Aspergillus spp. & $\begin{array}{l}\text { Aflatoxin B1a heptocarcinogen, strongly impair Liver to become yellowish in } \\
\text { color, fatty highly fibrous in appearance. }\end{array}$ \\
\hline 2 & Fumonisin & F. verticilloides & $\begin{array}{l}\text { Leukoencephalomalacia a disease commonly seen in horses that promotes } \\
\text { softening of the white matter in the brain leads to tumor. }\end{array}$ \\
\hline 3 & Sterigmatocystin & $\begin{array}{l}\text { A. versicolor } \\
\text { A. flavus } \\
\text { A. parasiticus }\end{array}$ & $\begin{array}{l}\text { Sterigmatocystin is a carcinogen, mostly contaminated with aflatoxin producing } \\
\text { species in fodder. }\end{array}$ \\
\hline 4 & Ochratoxin & $\begin{array}{l}\text { A. ohcraceus } \\
\text { P. viridicatum }\end{array}$ & $\begin{array}{l}\text { Ochratoxin } A(O A) \text { linked with a disease called Balkan nephropathy, human } \\
\text { carcinogen. Target organ are nephrons. }\end{array}$ \\
\hline 5 & Cyclopiazonicacid (CPA) & $\begin{array}{l}\text { P. cyclopium } \\
\text { A. flavus } \\
\text { A. oryzae }\end{array}$ & $\begin{array}{l}\text { Chemically, an indole tetrameric acid, often seen in association with aflatoxin } \\
\text { an inhibitor of calcium-dependent ATPases causes hemorrhagic lesions. }\end{array}$ \\
\hline 6 & Alternariols & Alternaria spp. & $\begin{array}{l}\text { Most common mold spore encountered growing on cement, wall paper, tile } \\
\text { grout, leaves, onions, tomatoes, corn, peanuts, fruits, vegetables, grain, etc. }\end{array}$ \\
\hline 7 & Patulin & P. patulinum & $\begin{array}{l}\text { Patulin is genotoxic polyketide lactone antiviral agent causing gastrointestinal } \\
\text { lesions. It relatively temperature stable even during pasteurization. It is come } \\
\text { across in apples and grapes, corn, and many berries. }\end{array}$ \\
\hline 8 & Tremorgens & P. crustosum Aspergillus spp. & $\begin{array}{l}\text { These mycotoxins cause "staggers" in man and animals. toxin-induced } \\
\text { gastroenteritis and neurotoxicity is commonly found in tremoragens } \\
\text { contaminant food like in animal feed, millets, corn, wheat, and nuts. }\end{array}$ \\
\hline 9 & Trichothecenes & Fusarium spp. & $\begin{array}{l}\text { T-2 toxins }(\mathrm{T}-2) \text { are sesquiterpene compounds exhibiting anti-leukemic } \\
\text { properties causes cellular death, and toxicosis in a short life span. T-2 is too } \\
\text { toxic to generally be reflected to be a warfare agent. }\end{array}$ \\
\hline 10 & Deoxynivalenol (DON) & F. graminearum & $\begin{array}{l}\text { DON (vomitoxin) responsible for emesis vomiting, because it causes gastro- } \\
\text { intestinal inflammation. DON infection leads to decreased weight loss, } \\
\text { anorexia, mal function nutritional efficiency and diminished immune system. }\end{array}$ \\
\hline 11 & Zearalenone & Fusarium spp. & $\begin{array}{l}\text { Zearalenone is a non-steroidal estrogenic potent mycotoxicoses causing } \\
\text { reproductive disorders in animals fed with contaminated fodder. Zearalenone is } \\
\text { seen in various parts of the globe (warm and cold climates) in grain crops. }\end{array}$ \\
\hline
\end{tabular}

Table 1: Types of Mycotoxins [8].

Aflatoxins: Aflatoxins are highly polyketide-derived, toxic and carcinogenic metabolites mainly produced by members of Aspergillus section $[9,10]$. There are nearly 20 various types of aflatoxins of which the four major aflatoxins consist of aflatoxins B1, B2, G1 and G2 produced by selected toxigenic strains isolates (not all isolates are toxigenic) of either Aspergillus flavus or A. parasiticus and often by Aspergillus nomius grow on various kinds of foods, and beverages. The aflatoxins were named from Aspergillus flavus (+toxin) as it emits blue colour when tested under UV light, aflatoxin G1 was the first green defined-spot). Aflatoxin B1 is about 3 times more toxigenic compared with AFG1. Aflatoxins are most prevalent in oil producing seed crops although it can occur any unfavorable condition. AFB1 and AFG1 are considered as Class I human heptocarcinogen, strongly impair Liver to become yellowish in color, fatty highly fibrous in appearance, functions are strongly impaired (Figure 1).

\section{Permissible limits of aflatoxins}

During 1960s, aflatoxins were listed under carcinogenic to laboratory test animals. FDA in 1969, (CAST, 2003) fixed $20 \mathrm{ppb}$ as level for aflatoxins at for all foodstuffs, in order to include animal feeds, based on FDA's agency and analytical capability.
Globally 50 countries formulated their own legislation regarding maximum permitted levels from 0 to $50 \mu \mathrm{g} / \mathrm{kg}$ of AF in food and feeds IARC (2012) [3,11], in food stuffs is $1-20 \mathrm{ppb}$ and in the feed the permissible limit range is $0-50 \mathrm{ppb}$. The limits for the aflatoxin M1 in the milk for human consumption are 0.05-0.5 ppb [1]. Maximum limits of $2 \mu \mathrm{g} / \mathrm{kg}$ for AFB1 and $4 \mu \mathrm{g} / \mathrm{kg}$ for total aflatoxins in herbal drugs have been set by the European Pharmacopoeia (EP, 2011).

Environmental factors affecting aflatoxin production: The growth of saprophytic species grown under water logging and humidity are favorable for asexual spores carried by wind or insects to the growing crop. When cereal crops such as wheat, barley, corn and oats growing moisture/humidity $(\mathrm{N} 14 \%)$ at warm temperatures $\left(\mathrm{N} 20^{\circ} \mathrm{C}\right)$, are liable for the crops to aflatoxin contamination.

Trichothecenes: Trichothecenes constitute a very vast group of mycotoxins having a tricyclic 12,13-epoxytrichothec-9-ene (EPT) ring system in collectively classified into four groups constructed on pattern of EPT (Types A, B, C and D) [12]. (T-2, HT-2, DON, DAS, NIV, and ZEN) produced by various species of moulds, in particular those belonging to the genus $F$ graminearum, $F$ culmorum, $F$. sporotrichioides, $F$ poae and $F$. equiseti are the most important 
trichothecene producing species. The main toxic effect of trichothecenes, at cellular level appears to be a primary inhibition of protein synthesis by action on peptidyl transferase activity interfering 60 subunit of the ribosome.

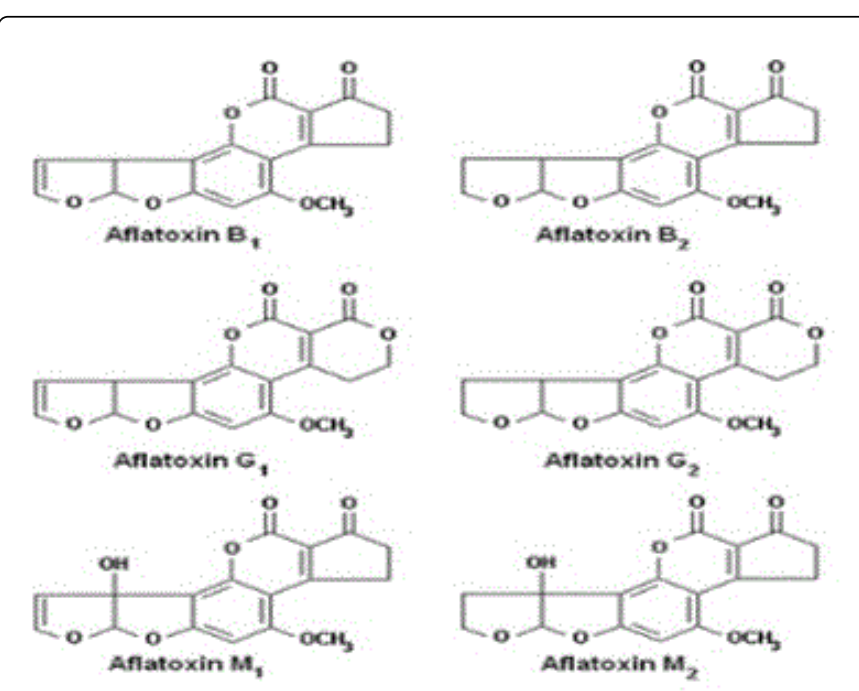

Figure 1: Structure of aflatoxin B (AFB1\& AFB2), G (AFG1\& AFG2), and M (AFM1\& AFM2).

\section{Types of Trichothecenes}

Trichothecenes are sesquiterpenoid mycotoxins with emetogenic properties, and harmful to hematopoietic organ and to immune function as they are effective inhibitors of eukaryotic protein pathway, with impact on global health and wealth. They are synthesized by a wide variety of mycogenic species comprising, Myrothecium, Stachybotrys, Fusarium, Cephalosporium, Trichoderma and Trichothecium.

The Type A trichothecenes (T-2 toxin (T-2) and HT-2 toxin (HT-2), and diacetoxyscirpenol (DAS)), produced by soil fungi and plant pathogens Fusarium acuminatum, F. poae, and F. sporotrichiodes, include T-2 toxin and HT-2 toxin, are the utmost toxigenic members of this mycotoxin family. Mostly type B tricho toxins, producers of $F$. graminearum and F. culmorum (Fusarenone-X (FUX), deoxynivalenol (DON), and nivalenol (NIV)), are fewer toxic compared to the afore Type A members, but are found at greater concentrations in cereal grains and foods. Based on the presence or absence of a carbonyl group at the $\mathrm{C} 8$ position trichothecene are differentiated in to types $\mathrm{A}$ and $\mathrm{B}$ [13]. Deoxynivalenol (DON, vomitoxin), is most prevalent worldwide acutely toxic trichothecene, because it is a very common contaminant.

Trichothecene heavy content dosages exposures in lab animals lead anorexia, gastro intestinal failures, leukocytosis, cardiac failure, which may ultimately cause death. Whereas moderate doses impairs food intake, reduces weight gain, disrupts immune function, hemostatic derangements [14], and can cause developmental effects.

T-2 Toxin: Trichothecene (T-2) also called as fusariotoxin T2, insariotoxin which have a common skeleton that includes a double bond between $\mathrm{C} 9$ and $\mathrm{C} 10$ and an epoxide group at $\mathrm{C} 12$ and C13inhibits DNA and RNA synthesis in vivo and in vitro [15], stress induce phosphokinase pathways, typically activate pro inflammatory gene expression, disrupt gastrointestinal function, and growth hormone tolerance, and cause cell death [16]. Topical application of T-2 toxin in mice [17] alters brain barrier permeability of blood. Tissue distribution studies suggest that liver is the major organ for metabolism of T-2 toxin. Once the toxin enters systemic circulation, regardless of route of exposure, it affects rapidly proliferating tissues. $\mathrm{T}-2$ toxin exposure by oral, parenteral, and cutaneous cause lesions in lymphoid, gastrointestinal tissues [18]. The involvement of oxidative stress and activation of various signaling pathways like MAP kinases, caspases have been shown in T-2 toxin induced apoptosis in vitro [19]. The main biotransformation pathway of T-2 toxin is deacetylation of C-4 acetyl groups to form HT-2 toxin [20] (Figure 2).

\begin{tabular}{l} 
Trichothecene \\
\hline Type $A$
\end{tabular}

Figure 2: Chemical structures of Trichothecenes and metabolites.

Deoxynivalenol (DON): Deoxynivalenol (DON, non-fluorescent), an immunosuppressive the most common trichothecene, is nonclassifiable as carcinogen to humans, however, it can cause deleterious health effects like anorexia, weight loss, malnutrition, endocrine dysfunction and immune alterations [16]. DON intake by human's ranges per day from 0.77 to $2.4 \mu \mathrm{g} / \mathrm{kg}$ body weight/day (FAO/WHO, 2001). In this regard, the provisional maximum tolerable daily intake (PMTDI) set for this mycotoxin and its acetylated derivatives is 1 $\mu \mathrm{g} / \mathrm{kg}$ body weight (b.w.) for general exposure, and $8 \mu \mathrm{g} / \mathrm{kg}$ b.w. for acute exposure (JECFA, 2001). DON-contaminated food intake may exhibit vomition syndrome in Humans [21] (Figure 3).

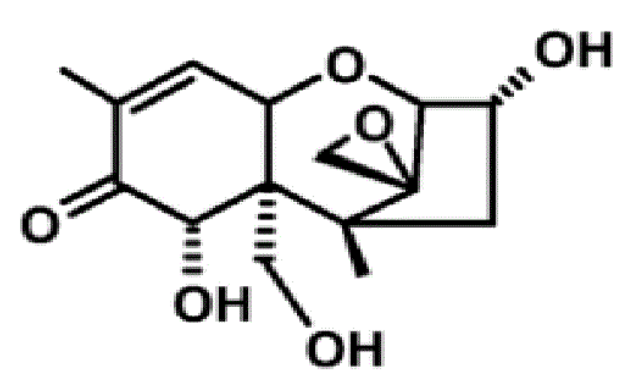

Figure 3: Chemical structure of Deoxynivalenol (DON).

Control of insect pests and good climatic storage conditions (14\% moisture), minimize contamination of will minimize toxigenic molds. Again, if grains have matured and are stored under appropriate conditions, DON does not further accumulate in storage. Baking and 
malting using contaminated wheat and barley are adversely affected [8]. European commission (EC, 2006) sets Permissible of limits Deoxynivalenol was $200 \mu \mathrm{g} / \mathrm{kg}$ for processed cereals and $1250 \mu \mathrm{g} / \mathrm{kg}$ for unprocessed cereals.

Ochratoxin: A fungal metabolite Ochratoxin was first discovered in 1965 as produced by different species of Penicillium verrucosum, $P$. nordicum, Aspergillus niger, $A$. quadrupole and $A$. carbonarius that showed toxic behavior towards animals. The family of ochratoxins consists of three members, $\mathrm{A}, \mathrm{B}$, and $\mathrm{C}$.

Ochratoxin A (OTA) is the most abundant and the most toxic of the three while ochratoxin B (OTB) and ochratoxin C (OTC) are less important and less common [22]. Frequent spoilage of cereals, vegetables, dried fruits, spices, coffee, fermented beverages was observed mainly because of OTA [23]. Environmental factors like temperature, moisture, incubation time, light effects the production of OTA [24]. Of the ochratoxin has equal importance as aflatoxins among Aspergillus toxins. OTA shown to be hepatotoxic, nephrotoxic, teratogenic, immunotoxic, and carcinogenic in experimental model. The mechanism of action seems to be related to the formation of DNA adducts [25]. Ochratoxin is a carcinogen in rats and mice and is suspect as the causative agent of human disease. Balkan Endemic Nephropathy is one such kidney disease, often with associated tumors, of humans that is considered by some to be caused by ochratoxin [26] (Figure 4).

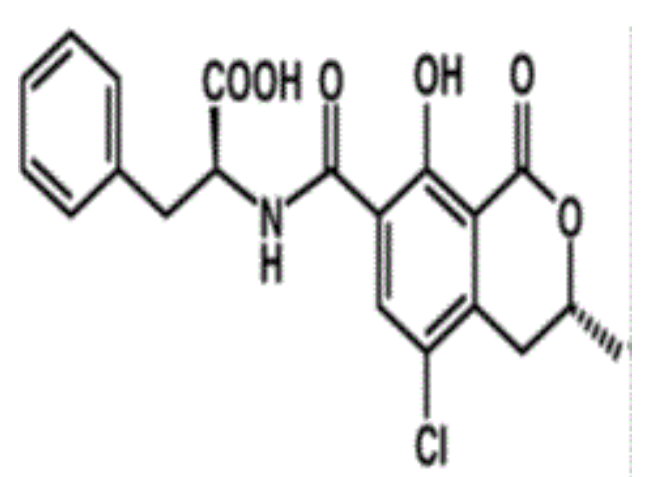

Figure 4: Structure of ochratoxin A.

Bui-Klimke et al. [27] calculated unadjusted odds ratios from epidemiological studies that correlated OTA exposure (measured by urinary OTA) with various adverse health endpoints.

Gilbert et al. [28] concluded urinary OTA levels with dietary OTA exposure shows adverse health endpoint significantly associated with nephritic syndrome. The review of the epidemiological data suggests that, there are no statistically considerable evidence for human health risks associated with OTA exposure [29]. Populations in which OTA exposures are extremely high (such as those studied in Egypt and Sierra Leone) may experience a significantly increased risk of nephritic syndrome. However, it is evident that extreme OTA contamination was not seen in most parts of the world from the tests of urinary OTA levels collected in multiple regions around the globe, hence the risk of OTA- nephritic syndrome is not expected to be significant on global scale.
The tolerable levels of OTA contamination for food items was formulated by European commission has described below: for dried fruits and soluble coffee $10.0 \mu \mathrm{g} \cdot \mathrm{kg}^{-1}$, for raw cereal grains and roasted coffee $5.0 \mu \mathrm{g} \cdot \mathrm{kg}^{-1}, 3.0 \mu \mathrm{g} \cdot \mathrm{kg}^{-1}$ for cereals intended for human consumption, $2.0 \mu \mathrm{g} \cdot \mathrm{kg}^{-1}$ for wine and grape juice and $0.5 \mu \mathrm{g} \cdot \mathrm{kg}^{-1}$ for baby foods and cereal based foods intended for young children (European Commission) [30]. The provisional tolerable intake of OTA weekly set up by The World Health Organization has established as 100 $\mathrm{ng} \cdot \mathrm{kg}^{-1}$ of body weight (equivalent to $14 \mathrm{ng} \cdot \mathrm{kg}^{-1}$ body weight/day) [31]. Thus sensitive, fast and selective detection methodologies are warranted in the field of human health care and for diagnostics of OTA.

Zearalenone: Zearalenone (ZEN) is a non-esteroidal estrogenic macrocyclic $\beta$-resorcyclic acid lactone is produced by Fusarium graminearum, Fusarium culmorum, Fusarium crokwellense, Fusarium sambucinum and Fusarium equiseti, in various parts of world [32]. The Fusarium sp. grow generally in moist cool conditions and similarly invade crops under these more favorable conditions. In wheat, sorghum and corn, zearalenone occurs in pre-harvest grain but in other commodities it is a bit insufficient to determine pre-or postharvest crops [33].

The structures of ZEN and its derivatives resemble $17 \beta$-estradiol and the potential for endocrine disruption has been evaluated using several models [34]. Early findings reported that ZEN induces genotoxic effects by induction of DNA-adducts, fragmentation, apoptosis [35], micronuclei, and chromosome aberrations, neurotoxic effects, proliferation and macronucleus synthesis in different cell lines [36] (Figure 5).

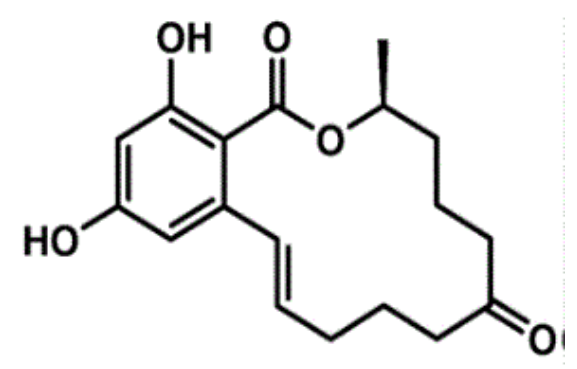

Figure 5: Structure of zearalenone.

The effects of ZEN on the central nervous system have received limited attention and therefore, a limited number of reports are available on their neurotoxicity [37]. The toxin also exerted its effects on astrocytes by regulating the plasma membrane reporters responsible for glutamate uptake. But no evaluation has been carried out on key regulators of brain function such as brain derived neurotrophic factor (BDNF); tyrosine hydroxylase (TH) and amino acid decarboxylase (AADC) which play a major role in brain functioning as well as neurotransmitter synthesis. Tyrosine hydroxylase or tyrosine 3-monooxygenase is the enzyme responsible for catalyzing the conversion of the amino acid L-tyrosine to L-3,4dihydroxyphenylalanine (L-DOPA) leads to neurotransmitter metabolism. The genes coding aromatic L-amino-acid decarboxylase deficiency (AADCD) is responsible for deficiency in neurotransmitter metabolism [38]. The decarboxylation of L-3,4dihydroxyphenylalanine (DOPA) is catalyzed by AADC encoded 
protein to dopamine, L-5-hydroxytryptophan to serotonin and $\mathrm{L}$ tryptophan to tryptamine.

ZEN and a-zearalenol (ZOL) are potential endocrine disruptors at picomolar levels influenced negatively the chromatin structural stability and viability of swine spermatic cells [39] by altering hormone signaling, production as measured by the H295R steroidogenesis assay [40].

ZEN and its derivatives induce an estrogen effect like proliferation of ER-positive human breast cells (MCF-7) [41]. Considering the capacity of these mycotoxins to interfere with the homeostasis [42], residues in agricultural products are a significant human health concern.

Gas chromatography triple quadrupole mass spectrometry (GCQqQ MS) substantially improves the selectivity and sensitivity compared to single-stage MS by eliminating chemical noise and isobaric interference [43]. Compared with ion-trap gas chromatography-tandem mass spectrometry, which has been applied for residue detection in agriculture products and foods [44], GC-QqQ MS is more stable and provides better quantitation results, especially for low levels in complex matrices.

Fumonisins: The fumonisins are heat-stable up to $\left(150^{\circ} \mathrm{C}\right)$ nonfluorescent group of mycotoxins derived from Fusarium, Liseola section, particularly grown in warmer regions. F. proliferatum, Fusarium verticillioides are the main producer of fumonisins around the globe at high temperate zones along with relatively high water activities. Mainly in maize under this extreme conditions $F$. napiforme, $F$. dlamini, $F$. nygamai, $F$. verticillioides and $F$. proliferatum grow well during pre and post-harvest storage stages [45]. B series (fumonisins B1, B2, and B3) analogues are having vast importance among 12 fumonisin series, among this fumonisin B1 is pertaining importance (CAST, 2003). During the process of fermentation, a little degradation of FBs is observed [45] (Figure 6).

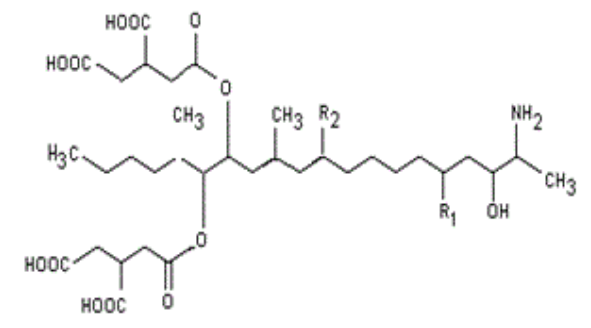

$\begin{array}{llllll} & \mathrm{R}_{1} & \mathrm{R}_{2} & \text { Fornula } & \text { CASNumber } & \text { Molecular mass } \\ \text { Funorisin } \mathrm{B}_{1} & \mathrm{OH} & \mathrm{OH} & \mathrm{C}_{34} \mathrm{H}_{59} \mathrm{NO}_{15} & 116355-83-0 & 721.838 \\ \text { Funonisin } \mathrm{B}_{2} & \mathrm{OH} & \mathrm{H} & \mathrm{C}_{34} \mathrm{H}_{59} \mathrm{~N}_{14} & 116355-84-1 & 705.839 \\ \text { Funonisin } \mathrm{B}_{3} & \mathrm{H} & \mathrm{OH} & \mathrm{C}_{34} \mathrm{H}_{59} \mathrm{NO}_{14} & 136379-59-4 & 705.839 \\ \text { Funonisin } \mathrm{B}_{4} & \mathrm{H} & \mathrm{H} & \mathrm{C}_{34} \mathrm{H}_{59} \mathrm{~N} \mathrm{~N}_{13} & 136379-60-7 & 689.840\end{array}$

Figure 6: Chemical structure of fumonisins.

Norred et al. [46] states that FB1 group, inhibits the catalysis of sphinganine (Sa) and recycling of sphingosine (So) which is mediated by enzyme ceramide (CER) synthase. Samples from animal species like tissues, urine, and blood are used as potential biomarkers of FBs (Sa to
So ratio) exposure, but studies have not allowed an accurate validation [47] (Figure 7).

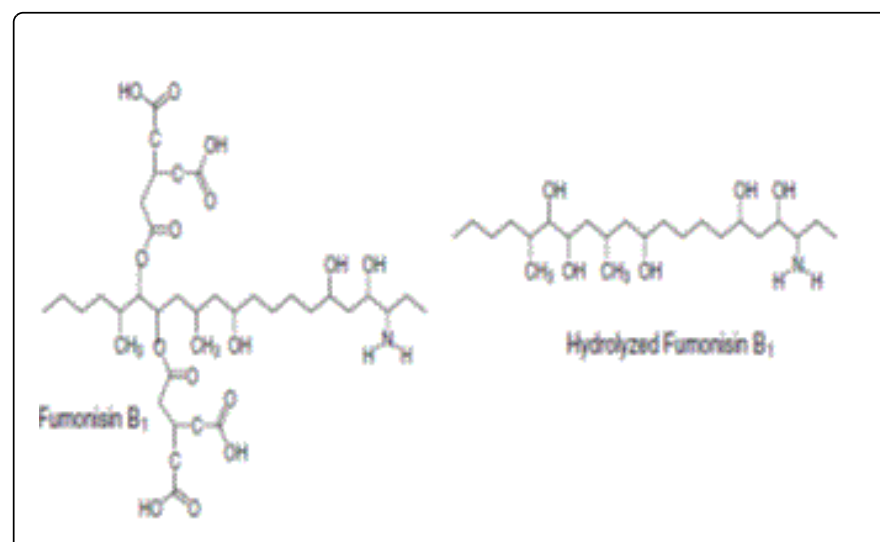

Figure 7: Hydrolyzed fumonisin B1.

The monotoxicity of FB1 on innate, humoral immunity, and cell response [48] changes in the expression of cell surface molecules, which are important in immune cell communication and NTDs [49] may be due to changes in various cytokines and chemokines in the immune system. The mechanism of action of FB1 induced NTDs [50] is the inhibition of uptake and metabolism of folic acid [51]. The fumonisins disturbs cellular signal pathways resulting from ceramide synthases inhibition which leads to carcinogenic effects in animals (JECFA, 2012). Fumonisins (FB1+FB2) levels in maize and maizebased foods for direct human consumption are regulated with a maximum level of $1000 \mu \mathrm{g} / \mathrm{kg}$ (EC, 2007). Fumonisins are stable at neutral $\mathrm{pH}$ and up to $175^{\circ} \mathrm{C}$, but as $\mathrm{pH}$ decreases and temperature increases above $175^{\circ} \mathrm{C}$ stability also decreases over $90 \%$. The exposure of FB1 on liver and esophageal [52] causes cancers in majority populations of liver cancer in China and South Africa [53]. Fumonisin $\mathrm{B} 1$ exposure to rodents above (P50 ppm) is hepato, nephron carcinogenic in male and female rats, [55] the major target organs are intestine, liver and kidney. Vander Westhuizen et al. [56] reported urinary FB1 excretion of $0.075 \%$ in humans. Although no hydrolyzed product has been found in urine or bile, it is assumed that hydrolysis occurs in the gut and is probably performed by microorganisms.

In horses and related species, a fatal disease known as Equine Leuko Encephalo Malacia syndrome characterized by the presence of liquefy active necrotic lesions in the white and grey matter of the cerebrum are observed which leads to blindness, and decreased feed intake followed by death after several hours or days [57].

The current analytical techniques available for FB1 primarily include instrumental analysis like high performance liquid chromatography (HPLC) [58], liquid chromatography/electrospray ionization mass spectrometry (LC/ESI-MS) [59], Gas chromatography (GC) and Fourier transform near infrared spectroscopy (FT-NIR) [60], and immunoassays like Enzyme-linked immunosorbent assay (ELISA) [61], and Gold immune chromatographic assay (GICA) [62]. The former techniques rely on expensive, sophisticated instrumentation and trained personnel, and require complicated sample preparation processes including extraction, cleanup, and/or derivatization. The latter methods are easier to be operated, but they cannot do without anti-FB1 antibodies. False positive or negative outcomes of immunoassays result from the characteristics of antibodies that they 
are sensitive to temperature and $\mathrm{pH}$ variation. Since its discovery by both Gold's group [63], aptamer technology has emerged as a novel approach to evolve nucleic acid recognition molecules alternative to antibodies for bioassay [64].

In 2007 European Union (EU) Commission finalized regulatory limits for sum of FB1 and FB2 in corn used food stuff with a maximum level $1000 \mathrm{ng} \mathrm{g}^{-1}$, in cereals $800 \mathrm{ng} \mathrm{g}^{-1}$ for human consumption. For infants and young children, the limits of exposure are $\left(200 \mathrm{ng} \mathrm{g}^{-1}\right)$. If these recommended levels are maintained in food stuffs the exposure of fumonisins can be regulated (FDA, 2001).

Ergot Alkaloids: Mycotoxins derived from prenylated tryptophan compounds characterized by a tetracyclic ergoline ring system released by fungal species Claviceps purpurea infect mainly cereals. There are four main groups of ergot alkaloids: the clavines, the lysergic acids, the lysergic acid amides, and the ergopeptides. Several Ascomycota fungi, representing two distantly related orders (Eurotiales and Hypocreales), produce ergot alkaloids.

The physiological effects of Ergot Alkaloids act as partial agonists [65] or antagonists at different adrenaline, noradrenaline, dopamine, and serotonin receptors they affect nervous, circulatory, reproductive, and immune systems [66]. Symptoms include reduced fertility, changes in blood pressure, lowered immune response, hallucinations, disturbances in sleep-wake cycles, and gangrene of the limbs [67] (Figure 8).

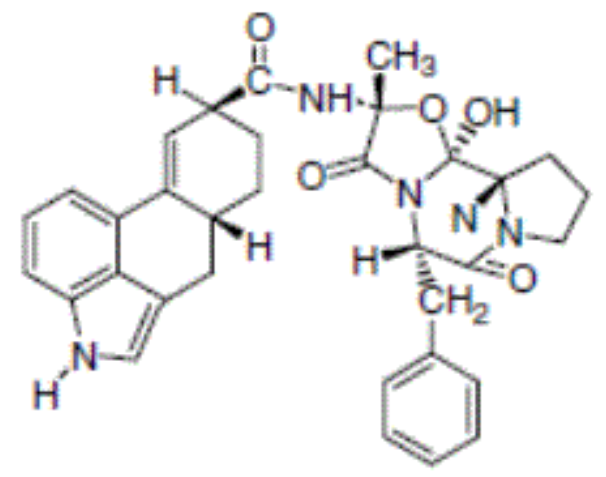

Figure 8: Chemical structure of Ergotamine.

Recent studies suggest that EAs contamination in fodder results in disturbance of gastrointestinal tract, neurotransmitter receptors, particularly adrenergic, dopaminergic, and serotonergic receptors subjected to oxidative biotransformation primarily by cytochrome P450 3A4, conjugated with glucuronic acid. Repeated dosing of EAs, to lab animals like rats results in decreased body weight, hormonal changes (EFSA, 2012). In more recent years, outbreaks have occurred in human populations and the effects included gangrene and loss of limbs and nervous signs including giddiness, drowsiness, nausea and vomiting $[68,69]$.

Patulin: Patulin, 4-hydroxy-4H-furo [3,2c] pyran-2(6H)-one, is mycotoxin released by variety of molds Penicillium, Aspergillus and Byssochlamys genera of which Penicillium expansum is a common contaminant of damaged fruits [70].
PAT has greater affinity towards sulfhydryl groups, which shows inhibitory activity on many enzymes which alters the intestinal barrier function and cause [71] gastric ulcers, vomiting and kidney damage [72]. Hence, PAT is concluded as genotoxic, mutagenic, and neurotoxic, in laboratory exposed rodents. PAT alters the immune system. The action of PAT on macrophage functions shows increasing number of splenic $\mathrm{T}$ lymphocytes and depressed serum immunoglobulin concentrations, hence increase in number of neutrophilsers [73].

JECFA - Joint FAO/WHO Expert Committee finalized maximum tolerable daily intake for patulin in Food Additives is $0.4 \mathrm{mg} / \mathrm{kg}$ of body weight per day [7] (Figure 9).

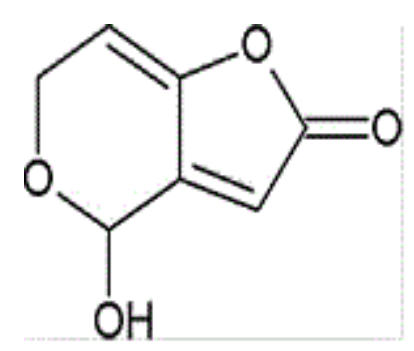

Figure 9: Chemical structure of patulin.

Other important mycotoxins with fewer occurrences: Other important mycotoxins that can be found as contaminants of foods include citreoviridin, gliotoxin, griseofulvin, mycophenolic acid, Kojic acid, walleminols, $\beta$-nitropropionic acid, penitrems, penicillic acid, viomellein, vioxantin and xanthomegnin.

The term "emerging mycotoxins" has been assigned recently, to toxins for which little knowledge was available in the routinely determined nor legislatively regulated past but now more research is focused to determine their occurrences and potential health effects. Mycotoxins in this group include fusaproliferin, beauvericin, enniatins and moniliformin. Recent findings about contamination of emerging toxins in feed ingredients were revealed, beauvericin was placed first followed by enniatins with the highest prevalence [74]. Due to the lack of research currently there are no regulations implemented to limit the presence of these mycotoxins in food additives (CAST, 2003).

Global trends of mycotoxin regulation: Majority countries of globe have implemented regulations to limit mycotoxin exposure that affect the consumer health and world wealth. In 2012 as per the annual report of the Rapid Alert System for Food and Feed (RASFF), border rejection notifications in the European Union is main hazard of mycotoxins. For instance, reviewed report compared the regulatory management of feed ingredients among the seven nations including approval and risk assessments entitled 'Comparison of Regulatory Management of Authorized Ingredients, Approval Processes, and RiskAssessment Procedures for Feed Ingredients' was written on behalf of the International Feed Industry Federation for the following jurisdiction that included European Union, Canada, Brazil, China, Japan, South Africa, and United States [75]. These steps involve the documentation and evaluation of regulatory procedures for feed ingredients (Table 2). 


\begin{tabular}{|l|l|l|l|l|}
\hline Hazard Category & Alert & Border Rejection & Information for attention & Information for follow up \\
\hline Allergens & 64 & 3 & 17 & 1 \\
\hline Biocont aminants & 6 & 9 & 26 & 2 \\
\hline Food additives and flavourings & 10 & 59 & 23 & 47 \\
\hline Foreign bodies & 24 & 61 & 26 & 47 \\
\hline GMO/Novel food & 2 & 52 & 14 & 22 \\
\hline Heavy metals & 57 & 108 & 79 & 24 \\
\hline Industrial contaminants & 16 & 9 & 18 & 14 \\
\hline Mycotoxins & 38 & 425 & 53 & 9 \\
\hline Parasitic infestation & 4 & 13 & 13 & 25 \\
\hline Pathogenic microorganisms & 162 & 159 & 168 & 103 \\
\hline Pestiside residues & 19 & 320 & 90 & 18 \\
\hline Residues of Veterinary medical products & 12 & 18 & 16 & 14 \\
\hline
\end{tabular}

Table 2: 2012 Notification by Hazard Category in the EU. Rapid alert system for food and feed (RASFF) Annual report 2012.

\begin{tabular}{|l|l|l|l|l|l|l|}
\hline Mycotoxin & 2008 & 2009 & 2010 & 2011 & 2012 & Total \\
\hline Aflotoxins & 902 & 638 & 649 & 585 & 484 & 3258 \\
\hline Deoxynivalenol (DON) & 4 & 3 & 2 & 11 & 4 & 24 \\
\hline Fumonisins & 2 & 1 & 3 & 4 & 4 & 14 \\
\hline Ocharatoxin & 20 & 27 & 34 & 35 & 32 & 148 \\
\hline Patulin & 3 & & & & & 3 \\
\hline Zearalenone & 2 & & & & 4 & 6 \\
\hline Total & 933 & 699 & 688 & 635 & 525 & 3450 \\
\hline
\end{tabular}

Strategies to prevent fungal toxins exposure: Avoidance of fungalcontaminated foods is a good way to prevent mycotoxin exposure, as they are microscopic and invisible to the naked eye. Even if visibly moldy, some populations are forced to consume contaminated foodstuffs in view of food security. Populations heavily reliant on singular staple crops prone to mold contamination are at highest risk for mycotoxin exposure.

Economy of various countries is related to the dietary diversity. Chen et al. [80] agricultural reforms demonstrate in China in 1980s led to diminished maize consumption resulted in a drastic reduction of $\mathrm{AF}$ exposure, which, independent of HBV vaccination, reduced the risk of primary liver cancer. This powerful evidence shows the astounding effect economics and policy has on cancer prevention. Nevertheless, economic change may be slow and unmanageable in certain parts of the world. Thus, multiple intervention strategies have been proposed to prevent and/or mitigate mycotoxin exposure. These include primary prevention strategies, which aim to avoid exposure and secondary intervention strategies, which modulate metabolism, thereby reducing the internal dose. Kensler et al. [11] recently reviewed primary and secondary intervention strategies that address AF exposure. Authors describe examples of primary prevention strategies, including the use of community education in post-harvest intervention trials [81] to reduce AF in groundnut crop and the use of NovaSil clay as an AF enterosorbent [82] and chlorophyllin as a trapping agent [83] to reduce the uptake of AF from the gastrointestinal tract.

Additionally, intervention trials using chemopreventive agents, oltipraz [84], sulforaphane, and green tea polyphenols [85] are described. In both primary and secondary strategies, AF biomarkers served to evaluate the effectiveness of intervention.

Economic impact of mycotoxins: Economic losses due to mycotoxins are diverse and can be associated with reduction of quality foods for humans and animals, reduction in animal production due to feed refusal or diseases, increasing medical cost for toxicosis treatments, increased costs to find alternative foods, to design adequate 
management to contain contaminated supplies, to improve detection and quantification methods and to develop strategies that reduce toxin exposure. A study by Robens and Cardwell in 2003, loss due to AF contaminated corn and peanuts, as well as FB contaminated corn and DON contaminated wheat resulted in estimated loss ranging from $\$ 0.5$ million to over $\$ 1.5$ billion for the U.S. [86]. Specifically for aflatoxins, Chinese studies aimed to evaluate the cost benefit of setting standard limits in different foods suggests that their applications might have significant effects in reducing liver cancer risk and food loss in that country [14]. It was concluded that following the CODEX Alimentarius standard at that time had less impacts in trade flow among the nations than if stringent E.U. rules were followed [87]. Global paddy production according to FAO for 2013 has been set at 746.4 million tonnes (497.6 million tonnes milled basis). Price for rice ranged from roughly 400 to 650 U.S. dollars for 5 different varieties just in July 2013 (FAO, 2013). It is evident that loss due to mycotoxins in this widely consumed cereal may have disastrous monetary impacts not just for the producers but for all of the world population.

Mycotoxins control: A control program for mycotoxins from field to table should involve the criteria of a HACCP approach which will require an understanding of the important aspects of the interactions of the toxigenic fungi with crop plants, the on-farm production and harvest methods for crops, the production of livestock using grains and processed feeds, including diagnostic capabilities for mycotoxicoses, and to the development of processed foods for human consumption as well as understanding the marketing and trade channels including storage and delivery of foods to the consumer's table. Common diagnostic and surveillance methods include culture, biochemical tests, and antibody based methods (e.g., agglutination and enzyme-linked assays) [88]. Definitive identification involves the amplification-based methods of regular and real-time PCR (quantitative PCR, or qPCR) [89]. Although fast and sensitive, PCR and qPCR are too complex to carry out in a basic clinical laboratory setting lacking highly-trained personnel. A good testing protocol for mycotoxins is necessary to manage all of the control points for finally being able to ensure a food supply free of toxic levels of mycotoxins for the consumer. There is continued need for point-of-care assays that are simple, sensitive, and economical.

Methodological issues: The contamination data often provided by researchers and consumption data from national dietary surveys are a common approach to evaluate the dietary exposure. These investigations are mainly useful to evaluate the nutritional status of the populations regarding energy and/or nutrients. From this survey we can estimate several food categories susceptible to contamination by mycotoxins. EFSA's Scientific Committee collects the large food consumption data over 5 years at an increasing level of detail. In 2008, EFSA formed the "Concise European Food Consumption Database" which is useful to improve Comprehensive European Food Consumption Database to be used for detailed exposure calculations in 22 different Member States (EFSA, 2011d). At individual level (73\%) and $27 \%$ at household level, a gold standard method $24 \mathrm{~h}$ duplicate diet was performed increasing precision at the expense of loss of representativeness [90]. This $24 \mathrm{~h}$ duplicate diet methodology was used to find out the exposure of children and adults to several mycotoxins [91-104].

\section{Conclusion}

Monitoring of food commodities for the presence of microbial hazards is a primary step in ensuring food safety. At international level, many countries have opted for regulation of mycotoxins in food commodities but in India no such efforts were made against Foodborne mycotoxins. Regulations on these toxins can be useful to comply with global market regulations in the near future. To control mycotoxins from contaminating food products there is a need for monitoring and control at different critical steps of the food chain to ensure food safety. These include food supply, monitoring during food processing monitoring of final products and also during storage. To find out the presence of mycotoxins in wide range of foodstuffs and their harmful effects to human health, research groups have devoted much effort to finding suitable mycotoxin detection techniques regarding food safety and quality requires a multidisciplinary approach based on a new generation of innovative and advanced technologies and tools to be used along the food chain for contaminants monitoring. In this review, we discuss the effects of mycotoxins on humans or animals some important aspects of toxicology and control have still resided in the realm of the unknown and unexplored. Only with continued research on understanding the effects and modes of mycotoxin action in various species, have regulations and control strategies been forthcoming.

\section{References}

1. FAO (2013) Mycotoxins. Food Safety and Quality.

2. (2013) United Nations Environmental Program (UNEP) GRID Adrenal, Food Demand and Need.

3. (2012) Chemical agents and related occupations: A review of human carcinogens, International Agency for Research on Cancer (IARC) 100F, IARC, Lyon, France.

4. (2001) Food and Agriculture Organization/World Health Organization, FAO/WHO, Safety evaluation of certain mycotoxins in food: prepared by the fifty-sixth meeting of the joint FAO/WHO Expert Committee on Food Additives (JECFA). WHO, Geneva.

5. Pitt JI, Wild CP, Baan RA, Gelderblom WCA (2012) Improving Public Health Through Mycotoxin Control. IARC Scientific Publication.

6. Fernandez-Cruz ML, Mansilla ML, Tadeo JL (2010) Mycotoxins in fruits and their processed products: analysis, occurrence and health implications. JAR 1: 113-122

7. Trucksess MW, Scott PM (2008) Mycotoxins in botanicals and dried fruits: a review. Food Addit Contam Part A Chem Anal Control Expo Risk Assess 25: 181-192.

8. Richard JL (2000) Mycotoxins-an overview. In: Richard, J.L. (ed.), Romer Labs' Guide to Mycotoxins 1: 1-48.

9. Passone MA, Rosso LC, Ciancio A, Etcheverry M (2010) Detection and quantification of Aspergillus section Flavi spp. in stored peanuts by realtime PCR of nor-1 gene, and effects of storage conditions on aflatoxin production. Int J Food Microbiol 138: 276-281.

10. Sardiñas N, Vázquez C, Gil-Serna J, González-Jaén MT, Patiño B (2011) Specific detection and quantification of Aspergillus flavus and Aspergillus parasiticus in wheat flour by $\mathrm{SYBR}^{\oplus}$ Green quantitative PCR. Int J Food Microbiol 145: 121-125.

11. Kensler TW, Roebuck BD, Wogan GN, Groopman JD (2011) Aflatoxin: a 50 -year odyssey of mechanistic and translational toxicology. Toxicol Sci 120 Suppl 1: 28-48.

12. Krska R, Baumgartner S, Josephs R (2001) The state-of-the-art in the analysis of type-A and -B trichothecene mycotoxins in cereals. Fresenius J Anal Chem 371: 285-299.

13. Schwarzer K (2009) Harmful effects of mycotoxins on animal physiology. In: 17th Annual ASAIM SEA Feed Technology and Nutrition Workshop, Hue, Vietnam.

14. Li Y, Wang Z, Beier RC, Shen J, De Smet D, et al. (2011) T-2 toxin, a trichothecene mycotoxin: review of toxicity, metabolism, and analytical methods. J Agric Food Chem 59: 3441-3453. 
15. (1990) Selected Mycotoxins: Ochratoxins Trichothecenes, Ergot. In: Environmental Health Criteria, WHO, Geneva.

16. Pestka JJ (2010) Deoxynivalenol: mechanisms of action, human exposure, and toxicological relevance. Arch Toxicol 84: 663-679.

17. Ravindran J, Agrawal M, Gupta N, Rao PV (2011) Alteration of blood brain barrier permeability by T-2 toxin: Role of MMP-9 and inflammatory cytokines. Toxicology 280: 44-52.

18. Creasia DA, Thurman JD, Wannemacher RW Jr, Bunner DL (1990) Acute inhalation toxicity of T-2 mycotoxin in the rat and guinea pig. Fundam Appl Toxicol 14: 54-59.

19. Chaudhari M, Jayaraj R, Bhaskar AS, Lakshmana Rao PV (2009) Oxidative stress induction by T-2 toxin causes DNA damage and triggers apoptosis via caspase pathway in human cervicalcancer cells. Toxicology 262: 153-161.

20. Königs M, Mulac D, Schwerdt G, Gekle M, Humpf HU (2009) Metabolism and cytotoxic effects of T-2 toxin and its metabolites on human cells in primary culture. Toxicology 258: 106-115.

21. Bhat RV, Beedu SR, Ramakrishna Y, Munshi KL (1989) Outbreak of trichothecene mycotoxicosis associated with consumption of moulddamaged wheat production in Kashmir Valley, India. Lancet 1: 35-37.

22. Van der Merwe KJ, Steyn PS, Fourie L (1965) Mycotoxins II The constitution of ochratoxins $\mathrm{A}, \mathrm{B}$, and $\mathrm{C}$, metabolites of Aspergillus ochraceus Wilh. J Chem Soc Perkin 1.

23. Janati SS, Beheshti HR, Asadi M, Mihanparast S, Feizy J (2012) Preliminary survey of aflatoxins and ochratoxin a in dried fruits from Iran. Bull Environ Contam Toxicol 88: 391-395.

24. Sanchis V, Magan N (2004) Environmental conditions affecting mycotoxins, CRC Press, Boca Raton Boston, New York, Washington, DC pp: 307-338.

25. Haighton LA, Lynch BS, Magnuson BA, Nestmann ER (2012) A reassessment of risk associated with dietary intake of ochratoxin A based on a lifetime exposure model. Crit Rev Toxicol 42: 147-168.

26. Pfohl-Leszkowicz A, Petkova-Bocharova T, Chernozemsky IN, Castegnaro M (2002) Balkan endemic nephropathy and associated urinary tract tumours: a review on aetiological causes and the potential role of mycotoxins. Food Addit Contam 19: 282-302.

27. Bui-Klimke TR, Wu F (2015) Ochratoxin A and human health risk: a review of the evidence. Crit Rev Food Sci Nutr 55: 1860-1869.

28. Gilbert J, Brereton P, MacDonald S (2001) Assessment of dietary exposure to ochratoxin A in the UK using a duplicate diet approach and analysis of urine and plasma samples. Food Addit Contam 18: 1088-1093.

29. Wafa EW, Yahya RS, Sobh MA, Eraky I, el-Baz M, et al. (1998) Human ochratoxicosis and nephropathy in Egypt: a preliminary study. Hum Exp Toxicol 17: 124-129.

30. Covarelli L, Beccari G, Marini A, Tosi L (2012) A review on the occurrence and control of ochratoxigenic fungal species and ochratoxin A in dehydrated grapes, non-fortified dessert wines and dried vine fruit in the Mediterranean area. Food Control 26: 347-356.

31. Quintela S, Villarán MC, de Armentia IL, Elejalde E (2013) Ochratoxin A removal in wine: A review. Food Control 30: 439-445.

32. Placinta CM, D'Mello JPF, Macdonald AMC (1999) A review of worldwide contamination of cereal grains and animal feed with Fusarium mycotoxins. Animal Feed Science and Technology 78: 21-37.

33. (2000) WHO Food Additives Series, Zearalenone, 53rd meeting of JECFA.

34. Heneweer M, Houtman R, Poortman J, Groot M, Maliepaard C, et al. (2007) Estrogenic effects in the immature rat uterus after dietary exposure to ethinylestradiol and zearalenone using a systems biology approach. Toxicol Sci 99: 303-314.

35. Abid-Essefi S, Baudrimont I, Hassen W, Ouanes Z, Mobio TA, et al. (2003) DNA fragmentation, apoptosis and cell cycle arrest induced by zearalenone in cultured DOK, Vero and Caco-2 cells: prevention by Vitamin E. Toxicology 192: 237-248.
36. Doi K, Uetsuka K (2011) Mechanisms of mycotoxin-induced neurotoxicity through oxidative stress-associated pathways. Int J Mol Sci 12: 5213-5237.

37. Razafimanjato H, Benzaria A, Taieb N, Guo XJ, Vidal N, et al. (2011) The ribotoxin deoxynivalenol affects the viability and functions of glial cells. Glia 59: 1672-1683.

38. Hyland K, Surtees RA, Rodeck C, Clayton PT (1992) Aromatic L-amino acid decarboxylase deficiency: clinical features, diagnosis, and treatment of a new inborn error of neurotransmitter amine synthesis. Neurology 42 : 1980-1988.

39. Benzoni E, Minervini F, Giannoccaro A, Fornelli F, Vigo D, et al. (2008) Influence of in vitro exposure to mycotoxin zearalenone and its derivatives on swine sperm quality. Reprod Toxicol 25: 461-467.

40. Frizzell C, Ndossi D, Verhaegen S, Dahl E, Eriksen G, et al. (2011) Endocrine disrupting effects of zearalenone, alpha- and beta-zearalenol at the level of nuclear receptor binding and steroidogenesis. Toxicology Letters 206: 210-217.

41. Minervini F, Giannoccaro A, Cavallini A, Visconti A (2005) Investigations on cellular proliferation induced by zearalenone and its derivatives in relation to the estrogenic parameters. Toxicology Letters 159: 272-283.

42. Massart F, Saggese G (2010) Oestrogenic mycotoxin exposures and precocious pubertal development. Int J Androl 33: 369-376.

43. Lambropoulou DA, Albanis TA (2007) Methods of sample preparation for determination of pesticide residues in food matrices by chromatography-mass spectrometry-based techniques: A review. Analytical and Bioanalytical Chemistry 389: 1663-1683.

44. Jiang JQ, Zhang L, Li GL, Zhang HT, Yang XF, et al. (2011) Analysis of 19nortestosterone residue in animal tissues by ion-trap gas chromatography-tandem mass spectrometry. J Zhejiang Univ Sci B, 12: 460-467.

45. (2005) European Food Safety Authority (EFSA), Opinion of the Scientific Committeee on a request from EFSA related to Exposure Assessments EFSA J 249: 1-26.

46. Norred WP, Plattner RD, Vesonder RF, Bacon CW, Voss KA (1992) Effects of selected secondary metabolites of Fusarium moniliforme on unscheduled synthesis of DNA by rat primary hepatocytes. Food Chem Toxicol 30: 233-237.

47. Solfrizzo M, Chulze SN, Mallmann C, Visconti A, De Girolamo A, et al. (2004) Comparison of urinary sphingolipids in human populations with high and low maize consumption as a possible biomarker of fumonisin dietary exposure. Food Addit Contam 21: 1090-1095.

48. Mahmoodi M, Alizadeh AM, Sohanaki H, Rezaei N, Amini-Najafi F, et al. (2012) Impact of fumonisin B1 on the production of inflammatory cytokines by gastric and colon cell lines. Iran J Allergy Asthma Immunol 11: 165-173.

49. Bouhet S, Le Dorze E, Peres S, Fairbrother JM, Oswald IP (2006) Mycotoxin fumonisin B1 selectively down-regulates the basal IL-8 expression in pig intestine: in vivo and in vitro studies. Food Chem Toxicol 44: 1768-1773.

50. Suarez L, Felkner M, Brender JD, Canfield M, Zhu H, et al. (2012) Neural tube defects on the Texas-Mexico border: what we've learned in the 20 years since the Brownsville cluster. Clin Mol Teratol 94: 882-892.

51. Stevens VL, Tang J (1997) Fumonisin B1-induced sphingolipid depletion inhibits vitamin uptake via the glycosylphosphatidylinositolanchored folate receptor. J Biol Chem 272: 18020-18025.

52. Sydenham EW, Thiel PG, Marasas WFO, Shephard GS, Schalkwyk DJ, et al. (1990) Natural occurrence of some Fusarium mycotoxins in corn from low and high esophageal cancer prevalence areas of Transkei, Southern Africa. J Agric Food Chem 38: 1900-1903.

53. Yoshizawa T, Yamashita A, Luo Y (1994) Fumonisin occurrence in corn from high- and low-risk areas for human esophageal cancer in China. Appl Environ Microbiol 60: 1626-1629.

54. Alizadeh AM, Rohandel G, Roudbarmohammadi S, Roudbary M, Sohanaki H, et al. (2012) Fumonisin B1 contamination of cereals and risk of esophageal cancer in a high risk area in northeastern Iran. Asian Pac J Cancer Prev 13: 2625-2628. 
55. Voss KA, Smith GW, Haschek WM (2007) Fumonisins, toxicokinetics, mechanism of action and toxicity. Anim Feed Sci Technol 137: 299-325.

56. Vander Westhuizen L, Shepard GS, Burger HM, Rheeder JP (2011) Fumonisin B1 as a urinary biomarker of exposure in a maize intervention study among South African subsistence farmers. Cancer Epidemiol Biomarkers Prev 20: 483-489.

57. Morgavi DP, Riley RT (2007) An historical overview of field disease outbreaks known or suspected to be caused by consumption of feeds contaminated with Fusarium toxins. Anim Feed Sci Technol 137: 201-212.

58. Shephard GS (1998) Chromatographic determination of the fumonisin mycotoxins. J Chromatogr A 815: 31-39.

59. Gazzotti T, Lugoboni B, Zironi E, Barbarossa A, Serraino A, et al. (2009) Determination of fumonisin B1 in bovine milk by LC-MS/MS. Food Control 20: 1171-1174.

60. Gaspardo B, Del Zotto S, Torelli E, Cividino SR, Firrao G, et al. (2012) A rapid method for detection of fumonisins $\mathrm{B} 1$ and $\mathrm{B} 2$ in corn meal using Fourier transform near infrared (FT-NIR) spectroscopy implemented with integrating sphere. Food Chem 135: 1608-1612.

61. Wang S, Quan Y, Lee N, Kennedy IR (2006) Rapid determination of fumonisin B1 in food samples by enzyme-linked immunosorbent assay and colloidal gold immunoassay. J Agric Food Chem 54: 2491-2495.

62. Shiu CM, Wang JJ, Yu FY (2010) Sensitive enzyme-linked immunosorbent assay and rapid one-step immunochromatographic strip for fumonisin B1 in grain-based food and feed samples. J Sci FoodAgric 90:1020-1026

63. Ellington AD, Szostak JW (1990) In vitro selection of RNA molecules that bind specific ligands. Nature 346: 818-822.

64. Wang J, Liu X (2012) Cost-benefit analysis in setting up limitation standards of aflatoxins in foods. Wei Sheng Yan Jiu 40: 150-153.

65. Panaccione DG, Ryan KL, Schardl CL, Florea S (2012) Analysis and modification of ergot alkaloid profiles in fungi. Methods Enzymol 515: 267-290.

66. Lorenz N, Haarmann T, Pazoutová S, Jung M, Tudzynski P (2009) The ergot alkaloid gene cluster: functional analyses and evolutionary aspects. Phytochemistry 70: 1822-1832.

67. Wallwey C, Li SM (2011) Ergot alkaloids: structure diversity, biosynthetic gene clusters and functional proof of biosynthetic genes. Nat Prod Rep 28: 496-510.

68. Demeke T, Kidane Y, Wuhib E (1979) Ergotism--a report on an epidemic, 1977-78. Ethiop Med J 17: 107-113.

69. Krishnamachari KA, Bhat RV (1976) Poisoning by ergoty bajra (pearl millet) in man. Indian J Med Res 64: 1624-1628.

70. Morales H, Sanchis V, Rovira A, Ramos AJ, Marin S (2007) Patulin accumulation in apples during postharvest: effect of controlled atmosphere storage and fungicide treatments. Food Control 18: 1443-1448.

71. Mahfoud R, Maresca M, Garmy N, Fantini J (2002) The mycotoxin patulin alters the barrier function of the intestinal epithelium, mechanism of action of the toxin and protective effects of glutathione. Toxicol Appl Pharmacol 181: 209-218.

72. Speijers GJ, Franken MA, van Leeuwen FX (1988) Subacute toxicity study of patulin in the rat: effects on the kidney and the gastro-intestinal tract. Food Chem Toxicol 26: 23-30.

73. Puel O, Galtier P, Oswald IP (2010) Biosynthesis and toxicological effects of patulin. Toxins 2: 613-631.

74. Streit E, Schwab C, Sulyok M, Naehrer K, Krska R, et al. (2013) Multimycotoxin screening reveals the occurrence of 139 different secondary metabolites in feed and feed ingredients. Toxins 5: 504-523.

75. Smedley KO (2013) Comparison of regulatory management of authorized ingredients, approval processes, and risk-assessment procedures for feed ingredients. Int Feed Indust Federation.

76. Ficheux AS, Sibiril Y, Parent-massin D (2012) Co-exposure of Fusarium mycotoxins: in vitro myelotoxicity assessment on human hematopoietic progenitors. Toxicon 60: 1171-1179.
77. Fess TL, Kotcon JB, Benedito VA (2011) Crop breeding for low input agriculture: a sustainable response to feed a growing world population. Sustainability 3: 1742-1772.

78. (2013) Food and Drug Administration (FDA), Foreing Supplier Verification Programs for Importers of Food for Humans and Animals.

79. (2013) Food and Drug Administration (FDA), Proposed Rule on Accreditation of Third Party Auditors.

80. Chen JG, Egner PA, Ng D, Jacobson LP, Munoz A, et al. (2013) Reduced aflatoxin exposure presages decline in liver cancer mortality in an endemic region of China. Cancer Prev Res 6: 1038-1045.

81. Turner PC, Sylla A, Gong YY, Diallo MS, Sutcliffe AE, et al. (2005) Reduction in exposure to carcinogenic aflatoxins by postharvest intervention measures in west Africa: a community-based intervention study. Lancet 365: 1950-1956.

82. Phillips TD, Afriyie-Gyawu E, Williams J, Huebner H, Ankrah NA, et al. (2008) Reducing human exposure to aflatoxin through the use of clay: a review. Food Addit Contam Part A Chem Anal Control Expo Risk Assess 25: 134-145.

83. Egner PA, Wang JB, Zhu YR, Zhang BC, Wu Y, et al. (2001) Chlorophyllin intervention reduces aflatoxin-DNA adducts in individuals at high risk for liver cancer. PNAS 58: 14601-14606.

84. Wang JS, Shen X, He X, Zhu YR, Zhang BC, et al. (1999) Protective alterations in phase 1 and 2 metabolism of aflatoxin B1 by oltipraz in residents of Qidong, People's Republic of China. J Natl Cancer Inst 91: 347-354.

85. Tang L, Tang M, Xu L, Luo H, Huang T, et al. (2008) Modulation of aflatoxin biomarkers in human blood and urine by green tea polyphenols intervention. Carcinogenesis 29: 411-417.

86. Robens J, Cardwell K (2003) The costs of mycotoxin management to the USA: management of aflatoxins in the United States. J Toxicol 22: 139-152.

87. Otsuki T, Wilson JS, Sewadeh M (2001) What price precaution? European harmonization of aflatoxin regulations and African groundnut exports. Eur Rev Agric Econ 28: 263-283.

88. Gerber MA, Shulman ST (2004) Rapid diagnosis of pharyngitis caused by group A streptococci. Clin Microbiol Rev 17: 571-580.

89. Lantz PG, Al-Soud WA, Knutsson R, Hahn-Hagerdal B, Radstrom P (2000) Biotechnical use of polymerase chain reaction for microbiological analysis of biological samples. Biotechnology annual review 5: 87-130.

90. Sizoo EA, van Egmond HP (2005) Analysis of duplicate 24-hour diet samples for aflatoxin B1, aflatoxin M1 and ochratoxin A. Food Addit Contam 22: 163-172.

91. Cano-Sancho G, Gauchi JP, Sanchis V, Marín S, Ramos AJ (2011) Quantitativedietary exposure assessment of the Catalonian population (Spain) to themycotoxin deoxynivalenol. Food Addit Contam A 28: 1098-1109.

92. Cano-Sancho G, Marín S, Ramos AJ, Sanchis V (2012) Exposure assessment of T2 and HT2 toxins in Catalonia (Spain). Food Chem Toxicol 50: 511-517.

93. Richard JL, Payne GA (2003) Mycotoxins: risks in plant, animal, and human systems, Council for Agricultural Science and Technology Task Force Report No. 139, Ames, Iowa, USA.

94. Cordeiro F, Baer I, Robouch P, Emteborg H, Can SZ, et al. (2013) Setting maximum limits for trace elements in baby food in European legislation: the outcome of International Measurement Evaluation Programme ${ }^{\varpi}-33$. Food Addit Contam Part A Chem Anal Control Expo Risk Assess 30: 678-686.

95. (2010) Commission Regulation (EU) No 1058/2012 of 12 November 2012 amending Regulation (EC) No 1881/2006 as regards maximum levels foraflatoxins in dried figs. Off J Eur Union L313:14-15.

96. (2006) European Commission Regulation (EC) No. 1881/2006 of 19 December 2006 setting maximum levels for certain contaminants in foodstuffs, 2006. Off J Eur Union L 364: 5-24.

97. (2007) European Commission Regulation (EC) No. $1126 / 2007$ of 28 September 2007 amending Regulation (EC) No 1881/2006 setting 
Citation: Sudhakar P, AswaniKumar YVV, Bodaiah B, Mangamu UK, Vijayalakshmi M and Renuka RM (2016) Mycotoxin Strategies: Impact on Global Health and Wealth. Pharm Anal Acta 7: 498. doi:10.4172/2153-2435.1000498

Page 11 of 11

maximum levels for certain contaminants in foodstuffs as regards Fusarium toxins in maize and maize products. Off J Eur Union L 255 14-17.

98. (2011) Council of Europe. European Directorate for the Quality of Medicines (EDQM) (7th edn) European Pharmacopoeia.

99. (2008) European Food Safety Authority (EFSA), Guidance Document for the use of the Concise European Food Consumption Database in Exposure Assessment p: 54.

100. (2011) European Food Safety Authority (EFSA), GUIDANCE of EFSA Use of the EFSA Comprehensive European Food Consumption Database in Exposure Assessment. EFSA J p: 2097.
101. (2001) Safety evaluation of certain food additives and contaminants. WHO/FAO Food Additives Series 48. International Programme on Chemical Safety (IPCS), WHO, Geneva.

102. (2006) Safety evaluation of certain contaminants in food, World Health Organization, FAO Food Nutr Pap, Geneva 82: 1-778.

103. Cigic IK, Prosen H (2009) An overview of conventional and emerging analytical methods for the determination of mycotoxins. Int J Mol Sci 10: 62-115.

104. Wang C, Yang G, Luo Z, Ding H (2009) In vitro selection of high-affinity DNA aptamers for streptavidin. Acta Biochim Biophys Sin 41: 335-340. 